\title{
Ocorrência de Campylobacter e Enterobacteriaceae em aves silvestres e frangos de corte
}

[Campylobacter and Enterobacteriaceae in wild birds and poultry]

\author{
P.A. Dias $^{1}$, T.P. Moraes $^{1}$, D.E. Wilsmann ${ }^{1}$, M.M. Ferrasso ${ }^{1}$, M.F. Marinheiro ${ }^{1}$, J.G. Heinen ${ }^{1}$, \\ C.I.P. Calabuig ${ }^{2}$, C.D. Timm ${ }^{1} *$
}

${ }^{1}$ Universidade Federal de Pelotas - Pelotas, RS

${ }^{2}$ Universidade Federal Rural do Semiárido - Mossoró, RN

\begin{abstract}
RESUMO
As aves silvestres podem ser reservatório de bactérias patogênicas e atuar como veiculadoras desses microrganismos para o ambiente, os animais domésticos e o homem. Portanto, o objetivo deste trabalho foi verificar a ocorrência de Campylobacter spp., Yersinia enterocolitica e Salmonella enterica em aves silvestres capturadas nas áreas próximas de aviários e em frangos de corte alojados nesses estabelecimentos, além de verificar a presença dos genes $c d t \mathrm{~A}, \quad c d t \mathrm{~B}$ e $c d t \mathrm{C}$ nos isolados de Campylobacter e identificar os sorotipos de Salmonella encontrados. Amostras de fezes de 189 aves silvestres capturadas com redes de neblina nas áreas próximas de 10 aviários e de 200 frangos de corte foram processadas para pesquisa de Campylobacter spp., S. enterica e Y. enterocolitica. Duas espécies de aves silvestres, Sicalis flaveola (canário-da-terra) e Zonotrichia capensis (tico-tico), foram positivas para Salmonella e Campylobacter, respectivamente. Foram isolados Campylobacter spp., S. enterica e Y. enterocolitica de frangos. Todos os isolados de Campylobacter analisados apresentaram os genes $c d t$. Em dois aviários, Campylobacter foi isolado tanto de frangos como de aves silvestres, entretanto a contaminação mútua entre essas aves não foi comprovada. Este foi o primeiro relato de isolamento de Campylobacter de Z. capensis e de Salmonella do sorotipo Derby de S. flaveola.
\end{abstract}

Palavras-chave: Campylobacter, Salmonella, Zonotrichia capensis, Sicalis flaveola

\begin{abstract}
Wild birds can be reservoirs of pathogenic bacteria and act as carriers of these microorganisms to the environment, domestic animals, and humans. Therefore, this study had as objective to verify the occurrence of Campylobacter spp., Yersinia enterocolitica and Salmonella enterica in wild birds captured in the surroundings of the aviaries and in the broilers housed in these establishments. The presence of the $c d t A, c d t B$ and $c d t C$ genes in Campylobacter isolates was also investigated and Salmonella serotypes were identified. Stool samples from 189 wild birds captured with mist nets in around 10 aviaries and from 200 broilers were processed for Campylobacter spp., S. enterica and Y. enterocolitica research. Two species of wild birds, Sicalis flaveola (Saffron Finch) and Zonotrichia capensis (Rufous-collared Sparrow) were positive for Salmonella and Campylobacter, respectively. Campylobacter spp., S. enterica and Y. enterocolitica were isolated from broilers. The cdt genes were found in all Campylobacter isolates. In two aviaries, Campylobacter was isolated from both broilers and wild birds, however the mutual contamination among these birds has not been shown. This was the first report of Campylobacter isolation from Z. capensis and of Derby Salmonella serotype isolation from S. flaveola.
\end{abstract}

Keywords: Campylobacter, Salmonella, Zonotrichia capensis, Sicalis flaveola

Recebido em 13 de setembro de 2017

Aceito em 17 de maio de 2018

*Autor para correspondência (corresponding author)

E-mail: timm@ufpel.tche.br 


\section{INTRODUÇÃO}

Salmonella enterica, Campylobacter jejuni e Yersinia enterocolitica estão entre os microrganismos mais comumente associados a toxinfecções alimentares envolvendo o consumo de produtos de origem animal (Marder et al., 2017). A importância da Salmonella em saúde pública está principalmente ligada à alta ocorrência do microrganismo em frangos de corte (Grant et al., 2016). Diferentemente da Salmonella, Campylobacter não é patogênico para as aves, o que faz com que seu controle seja negligenciado nos sistemas de produção avícola (Germano e Germano, 2015). Um dos fatores de patogenicidade de Campylobacter é a toxina citoletal distensiva (CDT). Essa toxina é composta pelas subunidades proteicas cdtA, cdtB e cdtC, codificadas pelos genes $c d t \mathrm{~A}, c d t \mathrm{~B}$ e $c d t \mathrm{C}$, respectivamente. É necessária a expressão dos três genes para que a proteína esteja na sua forma ativa e possa penetrar nas células (Jain et al., 2008).

Yersinia enterocolitica é considerado um patógeno emergente e a sua incidência como agente causador de diarreia, em alguns países, só é superada por Salmonella e Campylobacter (European Food Safety Authority, 2016). Entretanto, a sua ocorrência em aves, tanto domésticas como silvestres, tem sido pouco estudada.

As aves silvestres são consideradas reservatórios de Campylobacter, Salmonella e Yersinia (Kapperud e Rosef, 1983) e, devido a sua alta mobilidade, podem atuar como potenciais disseminadoras desses microrganismos para o meio ambiente e outros animais, sejam silvestres, domésticos ou o homem (Refsum et al., 2002b). Portanto, é de fundamental importância o conhecimento de quais espécies da avifauna podem albergar essas bactérias patogênicas. Por outro lado, as aves de produção podem representar fontes potenciais de contaminação para a fauna silvestre e o homem (Newman et al., 2007; Pennycott et al., 2006). Assim, o objetivo deste trabalho foi verificar a ocorrência de Campylobacter spp., Y. enterocolitica e $S$. enterica em aves silvestres capturadas nas áreas próximas de aviários e em frangos de corte alojados nos mesmos estabelecimentos, buscando estabelecer uma relação entre a contaminação das aves domésticas e das silvestres.

\section{MATERIAL E MÉTODOS}

O estudo foi desenvolvido em 10 aviários da região sul do estado do Rio Grande do Sul, que trabalham com galpões com lotação entre 5.200 e 5.400 frangos $\left(10 \mathrm{aves} / \mathrm{m}^{2}\right)$. Foram coletadas amostras de fezes de aves silvestres capturadas no entorno dos galpões onde os frangos estavam alojados. Para a coleta de fezes de aves silvestres de diferentes espécies passíveis de captura, quatro redes de neblina de $12 \mathrm{~m}$ com malha de $30 \mathrm{~mm}$ foram colocadas em locais estratégicos no entorno dos aviários. As redes permaneceram abertas durante quatro períodos (duas manhãs e duas tardes) de quatro horas, totalizando $16 \mathrm{~h}$, sendo revisadas em intervalos de tempo não superiores a $30 \mathrm{~min}$. Todas as aves capturadas nas redes tiveram amostras de fezes coletadas diretamente da cloaca com o uso de zaragatoas estéreis. Após, as aves silvestres foram identificadas taxonomicamente quanto ao gênero e à espécie, de acordo com a Lista comentada das aves do Brasil pelo Comitê Brasileiro de Registros Ornitológicos (Piacentini et al., 2015), anilhadas com anilhas fornecidas pelo Centro Nacional de Pesquisa e Conservação de Aves Silvestres (Cemave) e soltas imediatamente. Também foram coletadas amostras de fezes dos frangos que estavam nos aviários durante $\mathrm{o}$ período em que as aves silvestres foram capturadas. De cada aviário, foram coletadas 20 amostras de fezes de frangos, obtidas diretamente da cloaca das aves com o uso de zaragatoas estéreis, um dia antes do embarque para abate. As amostras de fezes foram encaminhadas ao laboratório em meio de transporte Cary Blair (Himedia, Mumbai, Índia), em caixas isotérmicas com gelo, e imediatamente processadas.

Para o isolamento de Campylobacter, as zaragatoas com as amostras de fezes foram diretamente semeadas em superfície de Columbia Blood Agar Base (Acumedia, Lansing, Michigan), adicionado de suplementos, conforme descrito por Silva et al. (2014). Os isolados foram criopreservados em meio estoque, constituído por $1 \mathrm{~mL}$ de soro fetal bovino (FBS, Gibco, Invitrogen), $1 \mathrm{~mL}$ de glicerol e $8 \mathrm{~mL}$ de caldo Mueller Hinton (Himedia, India), para serem recuperados quando necessário. 
Para pesquisa de Salmonella, as zaragatoas foram colocadas em tubos de ensaio com $10 \mathrm{~mL}$ de água peptonada tamponada (APT, Acumedia). O material foi incubado para pré-enriquecimento e demais procedimentos para pesquisa de Salmonella, conforme recomendado por U.S. Food and Drug Administration - FDA (Andrews et al., 2016).

Para pesquisa de $Y$. entrerocolitica, foi realizada semeadura por esgotamento em ágar MacConkey (Acumedia, Lansing, Michigan, USA) com a utilização da zaragatoa previamente obtida. Após incubação a $37^{\circ} \mathrm{C}$ por $24 \mathrm{~h}$, três colônias lactose negativas foram analisadas pela PCR para identificação da espécie.

Culturas em BHI de cada isolado identificado como Salmonella ou $Y$. entrerocolitica foram misturadas com $20 \%$ de glicerol para manutenção de estoque a $-70^{\circ} \mathrm{C}$.

O DNA dos isolados suspeitos de Campylobacter e de $Y$. enterocolitica (isolados lactose-negativa obtidos em ágar MacConkey) foi extraído conforme Sambrook e Russel (2001). A identificação de Campylobacter jejuni e C. coli foi feita por PCR, de acordo com protocolo descrito por Harmon et al. (1997), e a pesquisa dos genes $c d t \mathrm{~A}, c d t \mathrm{~B}$ e $c d t \mathrm{C}$ por multiplex PCR, segundo Martinez et al. (2006). A PCR para identificação de $Y$. enterocolitica foi realizada conforme Neubauer et al. (2000).

Os isolados de Salmonella foram encaminhados ao Departamento de Bacteriologia do Laboratório de Enterobactérias da Fundação Oswaldo Cruz (Fiocruz, Manguinhos, Rio de Janeiro) para identificação dos sorotipos por meio da determinação das estruturas somáticas e flagelares.

O trabalho foi aprovado pela Comissão de Ética em Experimentação Animal da Universidade Federal de Pelotas, recebendo o código para cadastro $n^{\circ} 6323$.

\section{RESULTADOS E DISCUSSÃO}

Foram estudados 10 aviários, nos quais foram amostradas 189 aves silvestres de 32 diferentes espécies e 200 frangos (Tab. 1).
Zonotrichia capensis (41 exemplares) e Sicalis flaveola (40 exemplares) foram as espécies mais frequentemente capturadas no presente estudo, correspondendo a $42,3 \%$ das capturas. Essas espécies, além de serem comuns na área de estudo, têm dieta predominantemente granívora, e a disponibilidade de alimento nos aviários deve ter sido fator determinante da sua presença em maior número nos locais de captura. Essas aves são de pequeno porte e, mesmo com o fechamento dos aviários com telas de malha não superior a 2,5cm (Brasil, 2009), elas conseguem acesso ao interior deles por pequenas frestas para alimentarem-se da ração fornecida aos frangos. Também foi possível observar a presença de aves silvestres no interior do aviário durante o período de vazio sanitário, quando ocorre o manejo da cama e limpeza de equipamentos. A interação entre aves silvestres e frangos de corte criados no Rio Grande do Sul também foi reportada por Scherer et al. (2011).

Foram isolados Campylobacter spp. e S. enterica de amostras de fezes de frangos e de aves silvestres, e $Y$. enterocolitica apenas de fezes de frangos (Tab. 2).

Os isolados de Campylobacter obtidos de amostras de aves silvestres foram oriundos de uma única espécie, $Z$. capensis, dos quais três foram identificados como $C$. coli e um como $C$. jejuni, sendo este o primeiro registro de isolamento de Campylobacter de Z. capensis. Nove isolados foram identificados morfológica e bioquimicamente como Campylobacter spp., mas, devido a dificuldades de cultivo da bactéria, não foi possível obter culturas com material suficiente para determinação da espécie pela PCR. Campylobacter possui um crescimento fastidioso in vitro e pode facilmente perder a capacidade de ser cultivado devido à exposição a condições desfavoráveis (Park, 2002). O estresse causado pela presença de oxigênio, temperatura baixa ou falta de nutrientes muda a morfologia das células para formas cocoides, que entram em um estado viável não cultivável, sendo incapazes de crescer em meios seletivos de isolamento (Lee e Newell, 2006). 
Dias et al.

Tabela 1. Espécies de aves silvestres capturadas nas áreas próximas aos aviários

\begin{tabular}{|c|c|c|c|c|c|c|c|c|c|c|c|c|}
\hline \multirow{2}{*}{$\begin{array}{l}\text { Espécies } \\
\text { Nome científico }\end{array}$} & \multirow[b]{2}{*}{ Nome popular } & \multicolumn{10}{|c|}{ Aviários } & \multirow{2}{*}{$\begin{array}{c}\text { Tota } \\
1\end{array}$} \\
\hline & & 1 & 2 & 3 & 4 & 5 & 6 & 7 & 8 & 9 & 10 & \\
\hline Zonotrichia capensis & Tico-tico & 2 & 3 & 3 & 5 & 18 & 3 & 1 & 4 & 1 & 1 & 41 \\
\hline Sicalis flaveola & Canário-da-terra & 3 & 0 & 2 & 2 & 7 & 1 & 0 & 25 & 0 & 0 & 40 \\
\hline Columbina picui & Rolinha-picui & 1 & 4 & 5 & 1 & 0 & 0 & 1 & 4 & 1 & 0 & 17 \\
\hline Furnarius rufus & João-de-barro & 2 & 2 & 5 & 1 & 0 & 0 & 2 & 1 & 1 & 0 & 14 \\
\hline Columbina talpacoti & Rolinha-roxa & 5 & 1 & 1 & 0 & 0 & 1 & 0 & 0 & 1 & 0 & 9 \\
\hline Lanio cucullatus & Tico-tico-rei & 0 & 1 & 0 & 0 & 0 & 2 & 1 & 3 & 0 & 1 & 8 \\
\hline Turdus amaurochalinus & Sabiá-p & 4 & 0 & 0 & 0 & 0 & 2 & 2 & 0 & 0 & 0 & 8 \\
\hline Turdus rufiventris & Sabiá-laranjeira & 1 & 3 & 1 & 1 & 0 & 1 & 0 & 0 & 0 & 0 & 7 \\
\hline Agelaioides badius & Asa-de-telha & 1 & 0 & 1 & 0 & 0 & 2 & 2 & 0 & 0 & 0 & 6 \\
\hline Troglodytes musculus & Corruíra & 0 & 1 & 0 & 0 & 0 & 4 & 0 & 0 & 0 & 1 & 6 \\
\hline Elaenia parvirostris & $\begin{array}{l}\text { Guaracava-de-bico- } \\
\text { curto }\end{array}$ & 1 & 1 & 0 & 0 & 0 & 0 & 2 & 1 & 0 & 0 & 5 \\
\hline Saltator similis & Trinca-ferro & 0 & 0 & 0 & 0 & 0 & 1 & 0 & 0 & 2 & 0 & 3 \\
\hline Molothrus bonariensis & Vira-b & 1 & 0 & 0 & 0 & 1 & 0 & 0 & 0 & 0 & 0 & 2 \\
\hline Pipraeidea bonariensis & Sanhaço-papa-laranja & 0 & 0 & 1 & 1 & 0 & 0 & 0 & 0 & 0 & 0 & 2 \\
\hline Parula pitiayumi & Mariquita & 0 & 1 & 0 & 0 & 0 & 0 & 0 & 1 & 0 & 0 & 2 \\
\hline Passer domesticus & Pardal & 0 & 0 & 0 & 0 & 0 & 0 & 1 & 1 & 0 & 0 & 2 \\
\hline Pitangus sulphuratus & Bem-te-vi & 0 & 0 & 0 & 1 & 1 & 0 & 0 & 0 & 0 & 0 & 2 \\
\hline Camptostoma obsoletum & Risad & 0 & 0 & 0 & 0 & 0 & 0 & 0 & 0 & 1 & 0 & 1 \\
\hline Chiroxiphia caudata & Tangará & 0 & 0 & 0 & 0 & 0 & 1 & 0 & 0 & 0 & 0 & 1 \\
\hline Chloroceryle americana & Marti & 0 & 0 & 0 & 0 & 0 & 0 & 0 & 1 & 0 & 0 & 1 \\
\hline Coereba flaveola & Cambacica & 0 & 1 & 0 & 0 & 0 & 0 & 0 & 0 & 0 & 0 & 1 \\
\hline Colaptes melanochloros & Pica-pau-verde-barrado & 0 & 0 & 0 & 0 & 0 & 0 & 1 & 0 & 0 & 0 & 1 \\
\hline Basileuterus culicivorus & Pula-pula & 0 & 0 & 0 & 0 & 0 & 0 & 0 & 0 & 0 & 1 & 1 \\
\hline Guira guira & Anu- & 0 & 0 & 0 & 0 & 0 & 0 & 0 & 0 & 1 & 0 & 1 \\
\hline Micro & Que & 0 & 0 & 0 & 0 & 0 & 1 & 0 & 0 & 0 & 0 & 1 \\
\hline urantiirostris & Bico & 0 & 0 & 0 & 0 & 0 & 0 & 1 & 0 & 0 & 0 & 1 \\
\hline hila caerulescens & Colc & 0 & 0 & 0 & 0 & 0 & 0 & 0 & 1 & 0 & 0 & 1 \\
\hline Tachyphonus coronatus & Tiê-p & 0 & 0 & 0 & 1 & 0 & 0 & 0 & 0 & 0 & 0 & 1 \\
\hline Thamnophilus ruficapillus & $\begin{array}{l}\text { Choca-de-chapéu- } \\
\text { vermelho }\end{array}$ & 0 & 0 & 0 & 0 & 1 & 0 & 0 & 0 & 0 & 0 & 1 \\
\hline Tan₹ & Saíra- & 0 & 0 & 0 & 0 & 0 & 0 & 0 & 1 & 0 & 0 & 1 \\
\hline Tangara sayaca & Sanhaço-cinzento & 0 & 0 & 1 & 0 & 0 & 0 & 0 & 0 & 0 & 0 & 1 \\
\hline Vireo olivaceus & Juruviara & 0 & 1 & 0 & 0 & 0 & 0 & 0 & 0 & 0 & 0 & 1 \\
\hline Total & & 21 & 19 & 20 & 13 & 28 & 19 & 14 & 43 & 8 & 4 & 189 \\
\hline
\end{tabular}

Tabela 2. Número de aviários, animais amostrados e amostras positivas para Yersinia enterocolitica, Salmonella enterica e Campylobacter spp.

\begin{tabular}{|c|c|c|c|c|c|c|c|c|}
\hline \multirow[b]{2}{*}{ Aviários } & \multirow[b]{2}{*}{ Frangos } & \multirow[b]{2}{*}{$\begin{array}{c}\text { Aves } \\
\text { silvestres }\end{array}$} & \multicolumn{2}{|c|}{ Y. enterocolitica } & \multicolumn{2}{|c|}{ S. enterica } & \multicolumn{2}{|c|}{ Campylobacter spp. } \\
\hline & & & Frangos & $\begin{array}{c}\text { Aves } \\
\text { silvestres }\end{array}$ & Frangos & $\begin{array}{c}\text { Aves } \\
\text { silvestres }\end{array}$ & Frangos & $\begin{array}{c}\text { Aves } \\
\text { silvestres }\end{array}$ \\
\hline 1 & 20 & 21 & 2 & 0 & 0 & 0 & 0 & 0 \\
\hline 2 & 20 & 19 & 0 & 0 & 0 & 0 & 2 & 0 \\
\hline 3 & 20 & 20 & 0 & 0 & 0 & 1 & 0 & 0 \\
\hline 4 & 20 & 13 & 2 & 0 & 0 & 0 & 5 & 0 \\
\hline 7 & 20 & 14 & 0 & 0 & 0 & 0 & $2 *$ & 0 \\
\hline 8 & 20 & 43 & 0 & 0 & 0 & 0 & $7 *$ & $4 / 6 *$ \\
\hline 9 & 20 & 13 & 1 & 0 & 0 & 0 & 0 & 0 \\
\hline 10 & 20 & 4 & 0 & 0 & 0 & 0 & 0 & 0 \\
\hline Total & 200 & 189 & 5 & 0 & 3 & 1 & 19 & 13 \\
\hline
\end{tabular}

*Amostras analisadas apenas morfológica e bioquimicamente. 
Salmonella foi isolada de uma amostra de fezes coletada de $S$. flaveola. Ao contrário do que ocorre com os animais de produção, os relatos de isolamento de patógenos de origem alimentar em aves silvestres são raros e bastante variáveis quanto aos resultados. Na Noruega, durante o período de 1969 a 2000, Salmonella foi isolada de 470 espécies de aves, incluindo 441 pequenos pássaros, 15 gaivotas, cinco aves aquáticas, quatro rapinantes, três pombas e dois corvos (Refsum et al., 2002a). Vlahovic et al. (2004), na Croácia, após análise de amostras de 107 aves silvestres de várias espécies, obtiveram dois $(1,9 \%)$ isolamentos de $C$. jejuni de pomba (Columba livia) e oito (7,5\%) de Salmonella, dois de gavião (Buteo buteo), dois de corvo (Corvus frugilegus), um de gaivota (Larus ridibundus) e um de coruja (Strix aluco), sendo as frequências de isolamento consideradas baixas pelos autores. Hughes et al. (2008) isolaram Salmonella de 32 amostras obtidas de pequenos pássaros (Carduelis chloris, Carduelis spinus, Carduelis carduelis, Passer domesticus e Sturnus vulgaris), pombas (Streptopelia decaocto e Columba palumbus) e gaivotas (Larus ridibundus e Larus argentatus) no norte da Inglaterra. Por outro lado, Mirzaie et al. (2010) isolaram Salmonella de apenas 3,8\% (18/470) de pardais (Passer domesticus) capturados na região de Teerã, Irã. No Brasil, Dias et al. (2014), em estudo realizado no extremo sul do Rio Grande do Sul, isolaram Salmonella de seis (24\%) amostras de fezes, cinco de $C$. ruficapillus e uma de S. flaveola, de 25 analisadas. Os mesmos autores também isolaram Campylobacter de oito (32\%) amostras de fezes de C. ruficapillus. Com base nos resultados do presente estudo em relação a esses outros trabalhos, a prevalência de Campylobacter spp. e $S$. enterica em aves silvestres na região pode ser considerada baixa.

$Y$. enterocolitica não foi isolada das fezes de aves silvestres, embora tenha sido de frangos. A ocorrência dessa bactéria em aves silvestres não tem sido muito estudada. Castro-Silva et al. (2011) analisaram amostras de aves silvestres no litoral de Santa Catarina e não encontraram $Y$. enterocolitica.

Oito Campylobacter isolados de frangos foram identificados como $C$. jejuni, e dois como $C$. coli. A presença de Campylobacter já tem sido reportada em frangos da região (Gomes et al., 2006; Silva et al., 2014), assim como Salmonella
(Tejada et al., 2016). Nos aviários 5 e 8, Campylobacter foi isolado tanto de aves silvestres como de frangos, mas não possível realizar a comparação entre essas cepas para verificar a sua similaridade. Entretanto, considerando a ocorrência de aves silvestres portadoras de Campylobacter no entorno dos aviários, tendo acesso ao ambiente em que se encontravam os frangos, os quais albergavam o mesmo microrganismo, a possibilidade de contaminação entre as aves silvestres e as de produção não pode ser descartada. Segundo a sorotipificação realizada pela Fiocruz dos isolados de Salmonella, o isolado obtido das fezes de $S$. flaveola pertencia ao sorotipo Derby. Outros estudos que têm identificado sorologicamente Salmonella isolada de aves silvestres reportam os sorotipos Typhimurium, Enteritidis, Newport, Senftenberg, Paratyphi e Montevideo (Hughes et al., 2008; Mirzaie et al., 2010; Refsum et al., 2002a; Vlahovic et al., 2004). Este é o primeiro registro da ocorrência de $S$. Derby em $S$. flaveola. Embora os sorotipos Enteritidis e Typhimurium sejam relatados em outros trabalhos como os mais frequentes em aves silvestres (Hughes et al., 2008; Mirzaie et al., 2010), esses sorotipos não foram identificados no presente trabalho. Dos três isolados de frangos, dois pertenciam ao sorotipo Anatum. O outro foi identificado somente quanto ao sorogrupo, denominado $\mathrm{O}: 3,10$, por não ter sido detectado o antígeno flagelar. Tejada et al. (2016), ao estudarem frangos na mesma região deste trabalho, observaram maior ocorrência do sorotipo Schwarzengrund, seguido de Mbandaka. Os sorotipos Enteritidis e Typhimurium parecem não ser tão frequentes em frangos no sul do Rio Grande do Sul, como são em outros locais.

Todos os isolados de Campylobactyer apresentaram os genes $c d t$ e possuíam os três genes $c d t \mathrm{~A}, c d t \mathrm{~B}$ e $c d t \mathrm{C}$, sendo potencialmente capazes de produzir a toxina CDT. Segundo Jain et al. (2008), as cepas produtoras de CDT apresentam alto poder de aderência, maior capacidade invasiva e citotoxicidade. Portanto, embora a capacidade da bactéria de provocar doença independa da produção da toxina, cepas portadoras dos genes $c d t$ são capazes de induzir casos mais severos da enfermidade. Os genes $c d t \mathrm{~A}, c d t \mathrm{~B}$ e $c d t \mathrm{C}$ têm sido identificados na maioria dos isolados de Campylobactyer obtidos de aves domésticas (Silva et al., 2014) e de amostras clínicas de humanos (Van Deun et al., 
2007), o que reforça a importância da sua presença nos isolados das fezes de aves analisadas neste estudo. A presença desses genes indica que as cepas obtidas apresentam elevada patogenicidade, representando um perigo em potencial para humanos e demais animais domésticos ou silvestres, que entrem em contato direto ou indireto com os portadores.

\section{CONCLUSÕES}

Com base nos resultados encontrados, foi comprovado que $S$. flaveola e Z. capensis podem ser portadores de Salmonella e Campylobacter, respectivamente, e que esses microrganismos, bem como $Y$. enterocolitica, estão presentes em aviários da região sul do estado do Rio Grande do Sul. $S$. Derby e $S$. Anatum foram isoladas de frangos e $S$. flaveola, respectivamente. Todos os isolados de Campylobacter apresentaram os genes $c d t$, sendo potencialmente capazes de produzir a toxina CDT. A contaminação mútua entre aves silvestres e frangos de corte não foi comprovada. Entretanto, ainda são poucos os dados sobre os microrganismos patogênicos albergados por aves silvestres e sobre quais espécies podem contaminar ou ser contaminadas por animais de produção e o homem.

\section{REFERÊNCIAS}

ANDREWS, W.H.; WANG, H.; ANDREW, J.; HAMMACK, T. Salmonella. U.S. food and drug administration, bacteriological analytical manual. 2016. chap.5. Available in: <http://www.fda.gov/Food/FoodScienceResearch /LaboratoryMethods/ucm070149.htm>.

Accessed in: 30 Aug. 2017.

antimicrobial resistance and bacteriophage control in poultry. Food Microbiol., v.53, part B, p.104-109, 2016.

BRASIL. Ministério da Agricultura, Pecuária e Abastecimento. Instrução Normativa n.59, de 04 de dezembro de 2009, que altera a Instrução Normativa n.56, de 04 de dezembro de 2007. Brasília: [MAPA], 2009.

CASTRO-SILVA, M.A.; MANOEL, F.C.; KRUEGER, J.; BARREIROS, M.A. B. et al. Identificação de bactérias potencialmente patogênicas a humanos presentes em Sula leucogaster (Suliformes: Sulidae), no litoral de Santa Catarina, Brasil. Rev. Bras. Ornitol., v.19, p.520-524, 2011.
DIAS, P.A.; WILSMANN, D.E.; HEINEIN, J.G. et al. Primeiro relato de Salmonella enterica e Campylobacter spp. isolados de Garibaldis (Chrysomus ruficapillus) e Canário-da-terra (Sicalis flaveola) de vida livre. Rev. Inst. Adolfo Lutz, v.66, p.397-403, 2014.

EUROPEAN Food Safety Authority - EFSA. EU summary report on zoonoses, zoonotic agents and food-borne outbreaks 2015. EFSA J., v.14, p.4634, 2016.

GERMANO, P.M.L.; GERMANO, M.I.S. Agentes bacterianos de toxinfecções. In:

(Eds.). Higiene e vigilância sanitária de alimentos. 5.ed. São Paulo: Varela, 2015.

GOMES, F.R.; CURCIO, B.R.; LADEIRA, S.R.L. et al. Campylobacter jejuni occurrence in chicken fecal samples from small properties in Pelotas, southern of Brazil. Braz. J. Microbiol., v.37, p.375-378, 2006.

GRANT, A.; HASHEM, F.; PARVEEN, S. Salmonella and Campylobacter:

antimicrobial resistance and bacteriophage control in poultry. Food Microbiol., v.53, Part B, p.104-109, 2016.

HARMON, K.M.; RANSOM, G.M.; WESLEY, I.V. Differentiation of Campylobacter jejuni and Campylobacter coli by polymerase chain reaction. Mol. Cell. Probes, v.11, p.195-200, 1997.

HUGHES, L.A.; SHOPLAND, S.; WIGLEY, P. et al. Characterization of Salmonella enterica serotype Typhimurium isolates from wild birds in northern England from 2005-2006. BMC Vet. Res., v.4, p.4, 2008.

JAIN, D.; PRASAD, K.N.; SINHA, S.; HUSAIN, N. Differences in virulence attributes between cytolethal distending toxin positive and negative Campylobacter jejuni strains. J. Med. Microbiol., v.57, p.267-272, 2008.

KAPPERUD, G.; ROSEF, O. Avian wildlife reservoir of Campylobacter fetus subsp. jejuni, Yersinia spp., and Salmonella spp. in Norway. Appl. Environ. Microbiol., v.45, p.375-380, 1983.

LEE, M.D.; NEWELL, D.G. Campylobacter in poultry: filling an ecological niche. Avian Dis., v.50, p.1-9, 2006. 
MARDER, E.P.; CIESLAK, P.R.; CRONQUIST, A.B. et al. Incidence and trends of infections with pathogens transmitted commonly through food and the effect of increasing use of culture-independent diagnostic tests on surveillance - foodborne diseases active surveillance network, 10 U.S. Sites, 2013-2016. Morb. Mortal. Wkly Rep., v.63, p.328-332, 2017.

MARTINEZ, I.; MATEO, E.; CHURRUCA, E. et al. Detection of $c d t \mathrm{~A}, c d t \mathrm{~B}$, and $c d t \mathrm{C}$ genes in Campylobacter jejuni by multiplex PCR. Int. J. Med. Microbiol., v.296, p.45-48, 2006.

MIRZAIE, S.; HASSANZADEH, M.; ASHRAFI, I. Identification and characterization of Salmonella isolates from captured house sparrows. Turk. J. Vet. Anim. Sci., v.34, p.181186,2010

NEUBAUER, H.; HENSEL, A.; ALEKSIC, S.; MEYER, H. Identification of Yersinia enterocolitica with in the genus Yersinia. Syst. Appl. Microbiol., v.23, p.58-62, 2000.

NEWMAN, S.H.; CHMURA, A.; CONVERSE, K. et al. Aquatic bird disease and mortality as an indicator of changing ecosystem health. Mar. Ecol. Progr. Ser., v.352, p.299-309, 2007.

PARK, S.F. The physiology of Campylobacter species and its relevance to their role as foodborne pathogens. Int. J. Food Microbiol., v.74, p.177-188, 2002.

PENNYCOTT, T.W.; PARK, A.; MATHER, H.A. Isolation of different serovars of Salmonella enterica from wild birds in Great Britain between 1995 and 2003. Vet. Rec., v.158, p.817-820, 2006.

PIACENTINI, V.Q.; ALEIXO, A.; AGNE, C.E. et al. Lista comentada das aves do Brasil pelo Comitê Brasileiro de Registros Ornitológicos. Rev. Bras. Ornitol., v.23, p.91-298, 2015.
REFSUM, T.; HANDELAND, K.; BAGGESEN, D.L. et al. Salmonella in avian wildlife in Norway from 1969 to 2000. Appl. Environ. Microbiol., v.68, p.5595-5599, 2002a.

REFSUM, T.; HEIR, E.; KAPPERUD, G. et al. Molecular epidemiology of Salmonella enterica serovar Typhimurium isolates determined by pulsed field gel electrophoresis: comparison of isolates from avian wildlife, domestic animals, and the environment in Norway. Appl. Environ. Microbiol., v.68, p.5600-5606, 2002 b.

SAMBROOK, J.; RUSSEL, D.W. Molecular cloning: a laboratory manual. New York: Cold Spring Harbor Laboratory Press, 2001.

SCHERER, A.L.; SCHERER, J.F.M.; PETRY, M.V.; SANDER, M. Occurrence and interaction of wild birds at poultry houses in southern Brazil. Rev. Bras. Ornitol., v.19, p.74-79, 2011.

SILVA, D.T.; TEJADA, T.S.; CUNHA, C.C. et al. Ocorrência de Campylobacter em carne de frango, fezes de frango e humanas e pesquisa dos genes cdt. Arq. Bras. Med. Vet. Zootec., v.66, p.297-304, 2014.

TEJADA, T.S.; SILVA, C.S.J.; LOPES, N.A. et al. DNA profiles of Salmonella spp. isolated from chicken products and from broiler and human feces. 2013. Braz. J. Poult. Sci., v.18, p.57-63, 2016.

VAN DEUN, K.; HAESEBROUCK, F.; HEYNDRICKX, M. et al. Virulence properties of Campylobacter jejuni isolates of poultry and human origin. J. Med. Microbiol., v.56, p.12841289, 2007.

VLAHOVIC, K.; MATICA, B.; PAVLAK, I.B.M. et al. Campylobacter, Salmonella and Chlamydia in free-living birds of Croatia. Eur. J. Wildl. Res., v.50, p.127-132, 2004. 